\title{
Evaluation of Twenty Intestinal Microbiota Transplantation
}

\author{
Álvaro Zamudio Tiburcio ${ }^{1 *}$, Héctor Bermúdez Ruiz ${ }^{2}$ and Pedro Antonio Reyes López ${ }^{3}$ \\ ${ }^{1}$ Department of Gastroenterology, Intestinal Microbiota Transplantation Hospital Trinidad, Mexico \\ ${ }^{2}$ Department of Endoscopy, Intestinal Microbiota Transplantation Hospital Trinidad, Mexico \\ ${ }^{3}$ Department of Cardiology, Intestinal Microbiota Transplantation Hospital Trinidad, Mexico \\ *Corresponding author: Álvaro Zamudio Tiburcio, Department of Gastroenterology, México
}

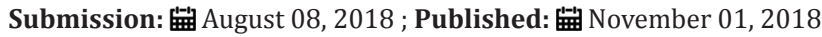

\begin{abstract}
We report 18 cases treated with 20 Intestinal Microbiota Transplantation (IMT), with good results. In one patient, 3 transplants were performed.16 patients of their primary condition improved, with percentages of 50 to $100 \%$. ELA has not advanced. The patient with Lupus remained stable: 30 days. The diverticular disease of the colon did not improve in the initial phase. It was noted that a patient with a diverticular disease of the colon that died 3 years after being transplanted, due to pulmonary embolism, as a complication of surgery due to intestinal obstruction, found the colon in perfect condition. Six patients attended with post-transplant diarrhea. 2, 4 and 5 daily evacuations, respectively, that yielded with probiotics in 3, 4, and 7 days.

Keywords: Anxiety; Irritable bowel syndrome; Fecal microbiota transplantation; Intestinal microbiota; Microbiota transplantation
\end{abstract}

\section{Introduction}

Undoubtedly, IMT has become a tool for managing health problems, not only in gastrointestinal diseases, but in pathologies of various devices and systems [1]. Although it is demonstrated that IMT is generous in recurrent and initial infections by $C$. difficile [2]. It is also useful in other pathologies, among which stress anxiety, IBS, IBD and others [3].

\section{Cases}

We report 18 patients treated with 20 IMT from August 2015 to date ( 1 case required 3 transplants). We found that the most frequent pathology was anxiety, followed by IBS. There were 10 men and 8 women, with ages ranging from 35 to 83 years. The main condition was in 11 patients Anxiety; 3 IBS, 4: pseudomembranous enterocolitis, intestinal malabsorption syndrome, amyotrophic lateral sclerosis (ALS) and disseminated lupus erythematosus, respectively. 16 patients of their primary condition improved, with percentages of 50 to $100 \%$.

\section{Discussion}

The first experience of microbiota transplantation was to treat diarrhea, followed by the management of severe diarrhea due to Clostridium difficile, plus what happened to the rest of the illnesses handled with this methodology?

One of the conditions is the recurrence of diarrhea due to Clostridium difficile [4]. It has been observed that a second or sometimes a third use of the Microbiota Transplantation has controlled this type of diarrhea, although in most cases, a first attempt is enough [5]. Diarrhea alone or associated with IBS has also been considered within the conditions that have been treated with IMT, with various results [6]. In the world literature there are innumerable articles that have been written in relation to IMT, especially in regard to Clostridium difficile diarrhea, but, now, which conditions are improved when treated with IMT?

\section{Conclusion}

Our group is a pioneer in Latin America in managing IMT for another type of pathology. We only include a case with Clostridium difficile, which cured with 3 IMT. We have good results in other types of pathologies, both digestive and extra-digestive. We started the use of Intestinal Microbiota as a transplant as of August 2015. Our casuistry is scarce, due to the fact that in the particular environment, it is not easy for a patient to access the IMT, especially due to lack of economic resources. Generally, they are not afraid that they will be transplanted with fecal material, since they are made to read medical information before the IMT and they are cleared of all kinds of questions. Once they observe the overwhelming amount of information on the internet, they are positively surprised and easily adopt the procedure.

\section{Conflicts of Interest}

The authors declare have no affiliations or involvement in organizations with a financial interest.

\section{Ethical Approval}

The present report does not contain any studies with human subjects or animals performed by the authors. 


\section{References}

1. Reid G, Younes JA, Van der Mei HC, Gloor GB, Knight R, et al. (2011) Microbiota restoration natural and supplemented recovery of human microbial communities. Nat Rev Microbiol 9(1): 27-38.

2. Mai V, Young CM, Ukhanova M, Wang X, Sun Y, et al. (2011) Fecal microbiota in premature infants prior to necrotizing enterocolitis. PloS one 6(6): e20647.

3. Sarra M, Pallone F, Macdonald TT, Monteleone G (2010) IL-23/IL-17 axis in IBD. Inflamm Bowel Dis 16(10): 1808-1813.
4. Kamada N, Seo SU, Chen GY, Nunez G (2013) Role of the gut microbiota in immunity and inflammatory disease. Nat Rev Immunol 13(5): 321-335.

5. Reid G, Younes JA, Van der Mei HC, Gloor GB, Knight R, et al. (2011) Microbiota restoration natural and supplemented recovery of human microbial communities. Nat Rev Microbiol 9(1): 27-38.

6. Bauer MP, Van Dissel JT (2009) Alternative strategies for Clostridium difficile infection. Int J Antimicrob Agent 33 Suppl 1: S51-S56.

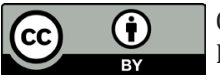

Creative Commons Attribution 4.0 International License

For possible submissions Click Here

\section{Submit Article}

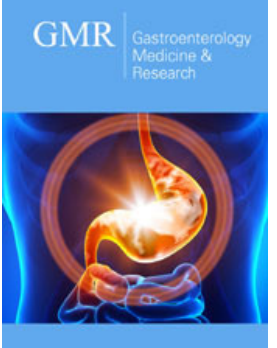

Gastroenterology Medicine \& Research

\section{Benefits of Publishing with us}

- High-level peer review and editorial services

- Freely accessible online immediately upon publication

- Authors retain the copyright to their work

- Licensing it under a Creative Commons license

- Visibility through different online platforms 